\title{
Prevalence and intensity of helminths among inhabitants of the Chi River and Lahanna water reservoir areas of Northeastern Thailand
}

\author{
Rattanapitoon, S.K. ${ }^{1,2^{*}}$, Pechdee, P. ${ }^{1,2,3}$, Boonsuya, A. ${ }^{1,2}$, Meererksom, T. ${ }^{1,2}$, Wakkhuwatapong, P. ${ }^{1}$, \\ Leng, M.1,2, Namhong, T. ${ }^{1,2}$, Taweepakdeechot, A. ${ }^{1,2}$, Yardcharoen, N. ${ }^{1,2}$, Srithongklang, W. ${ }^{1,2}$, La, N. ${ }^{1,2}$, \\ Keeratibharat, N. ${ }^{1,2}$, Chansangrat, J. ${ }^{1,2}$, Asavaritikrai, P.,2 and Rattanapitoon, N.K. ${ }^{1,3}$ \\ ${ }^{1}$ Parasitic Disease Research Center, Suranaree University of Technology, Nakhon Ratchasima 30000, Thailand \\ ${ }^{2}$ School of Translational Medicine, Institute of Medicine, Suranaree University of Technology, \\ Nakhon Ratchasima 30000, Thailand \\ ${ }^{3}$ Institute of Research and Development, Suranaree University of Technology, Nakhon Ratchasima 30000, \\ Thailand \\ *Corresponding author email: schawanya.ratt@sut.ac.th \\ Received 24 March 2020; received in revised form 18 July 2020; accepted 20 July 2020
}

\begin{abstract}
Helminth infections (HIs) are an important public health problem in tropical countries, and the associated problems have been neglected in rural areas of Thailand. Therefore, this study reports the prevalence and intensity of HIs among inhabitants of the Khon Sawan district, Chaiyaphum province, and Kaeng Samnam Nang district, Nakhon Ratchasima province, which are located near the Chi River and Lahanna water reservoir, northeastern Thailand. A cross-sectional descriptive study was conducted between July 31, 2018, and June 30, 2019, among rural villagers from 40 rural villages in 4 subdistricts. The participants were selected from the village enrolment list after proportional allocation of the total sample size. Faecal samples from 691 inhabitants were prepared using solvent-free faecal parasite concentrator, and helminths were then detected using a light microscope. Statistical analysis included the Chi-square test with Yates correction, and multivariable logistic regression was performed. A P-value of $<0.05$ was considered statistically significant. The prevalence of HIs was $2.03 \%$. The most prevalent helminths were Opisthorchis viverrini (1.31\%), followed by Strongyloides stercoralis (0.44\%), Ascaris lumbricoides (0.29\%), hookworm (0.15\%), Teania spp. (0.15\%) and one minute intestinal fluke (0.15\%). Coinfections were identified in 2 cases for $S$. stercoralis and hookworm and 1 case for $O$. viverrini and $S$. stercoralis infection. All infected participants had a light intensity of HI. There was no significant difference between general characteristics for all HIs. The prevalence of HIs was not significantly associated with general characteristics. This study indicates that the infections result mainly from foodborne helminths and skin-penetrating nematodes. Therefore, interventions should concentrate on the personal hygiene of the population and improving sanitation to reduce HIs in this area.
\end{abstract}

\section{INTRODUCTION}

Helminth infections (HIs) are widely distributed in tropical and subtropical areas, with the greatest numbers occurring in subSaharan Africa, the Americas, China and East Asia (World Health Organization, 2018). Statistics indicate that more than 1.5 billion people, or $24 \%$ of the world's population, are infected with soil-transmitted helminths
(STHs). In ASEAN countries, it is estimated that 300 million people are infected with HIs caused by STHs; specifically, 126.7 million people are infected with Ascaris lumbricoides, 115.3 million are infected with Trichuris trichiura, and 77.0 million are infected with hookworm (Hotez et al., 2015). More than 10 million people in ASEAN countries (particularly Thailand, Lao's People Democratic Republic, Cambodia, and 
Vietnam) suffer from either liver or intestinal fluke infections caused by foodborne helminths (FBHs) (Hotez et al., 2015). The HIs caused by liver flukes, including Opisthorchis viverrini and Clonorchis sinensis, are classified as group 1 carcinogens by the World Health Organization's International Agency for Research on Cancer (International Agency for Research on Cancer, 2011). In 2014, the national prevalence rate of HIs was $18.1 \%$ among 15,555 Thais, with a high prevalence rate of liver fluke and hookworm infections in certain areas of the country (Wongsaroj et al., 2014). Previous studies have assessed the prevalence and intensity of HIs among rural villagers in Waeng Noi district, Khon Kaen Province, northeastern Thailand, which is located near the Lahanna fresh water reservoir, and this area is adjacent to Nakhon Ratchasima and Chaiyaphum provinces. Of the 400 faecal specimens examined, 23 were positive for at least one intestinal helminth, resulting in a prevalence of $5.75 \%$. The most prevalent helminths were Taenia spp., 10 (2.50\%); followed by hookworm, 5 (1.25\%); T. trichiura, 4 (1.0\%); A. lumbricoides, 3 (0.50\%); and O. viverrini, $1(0.25 \%)$. This study reveals that HIs, particularly those from food-borne and soiltransmitted species of helminths, are prevalent in adults in rural subdistricts (Kaewpitoon et al., 2019). In addition, Kaewpitoon et al. (2016) reported the prevalence of $O$. viverrini infection among villagers in the border areas of three provinces in northeastern Thailand. In the 978 participants screened, O. viverrini infection was found in $1.74 \%$, and the majority of positive cases were found in participants who lived in the Khon Sawan district (8.43\%) and Kaeng Sanam Nang district (1.84\%). From this updated report, no information was available regarding the prevalence and intensity of HIs among the residents at the subdistrict level in Khon Sawan district, Chaiyaphum province, and Kaeng Sanam Nang district, Nakhon Ratchasima province, especially in the villages located near the Chi River and Lahanna fresh water reservoir. Consequently, this study was undertaken to determine the prevalence and intensity of HIs among people living in four districts from two provinces in the northeastern region of Thailand. These data are useful for further intervention and research approaches in the study area.

\section{MATERIALS AND METHODS}

\section{Ethics statements}

This study was approved by the Ethics Committee for Research Involving Human Subjects of Suranaree University of Technology, Thailand (EC- 59-38).

\section{Study design and area}

A cross-sectional survey was carried out from July 31, 2018, to June 30, 2019, and included people living in 40 rural villages located in the Yang Wai (7 villages) and Kok Mang Ngoy (11 villages) subdistricts, Khon Sawan district, Chaiyaphum province, and in Bueng Phalai (11 villages) and Bueng Samrong (9 villages) subdistricts, Kaeng Sanam Nang district, Nakhon Ratchasima province, northeastern Thailand. The study areas are located $376.4 \mathrm{~km}$ (Khon Sawan) and $341.3 \mathrm{~km}$ (Kaeng Sanam Nang) northeast of Bangkok and cover an area of $776.1 \mathrm{~km}^{2}$ (Figure 1). Four subdistricts are located near the Chi River (which is $765 \mathrm{~km}$ long and the longest river flowing wholly within Thailand), and the Lahanna fresh water reservoir (which covers $11.2 \mathrm{~km}^{2}$ of the catchment area for water from the Chi River). Participants were selected from each village using a voluntary sampling method. A total of 691 volunteers were recruited from Yang Wai (n=210), Kok Mang Ngoy ( $n=213)$, Bueng Phalai $(n=176)$ and Bueng Samrong $(n=92)$. Data on sociodemographic characteristics were collected using a questionnaire. All participants provided their own written consent before submitting stool specimens.

\section{Faecal collection and examination}

Clean plastic containers were distributed to the participants at enrolment with detailed instructions about the procedure for faecal specimen collection. All faecal samples were collected early in the morning and stored in coolers before transportation to the 


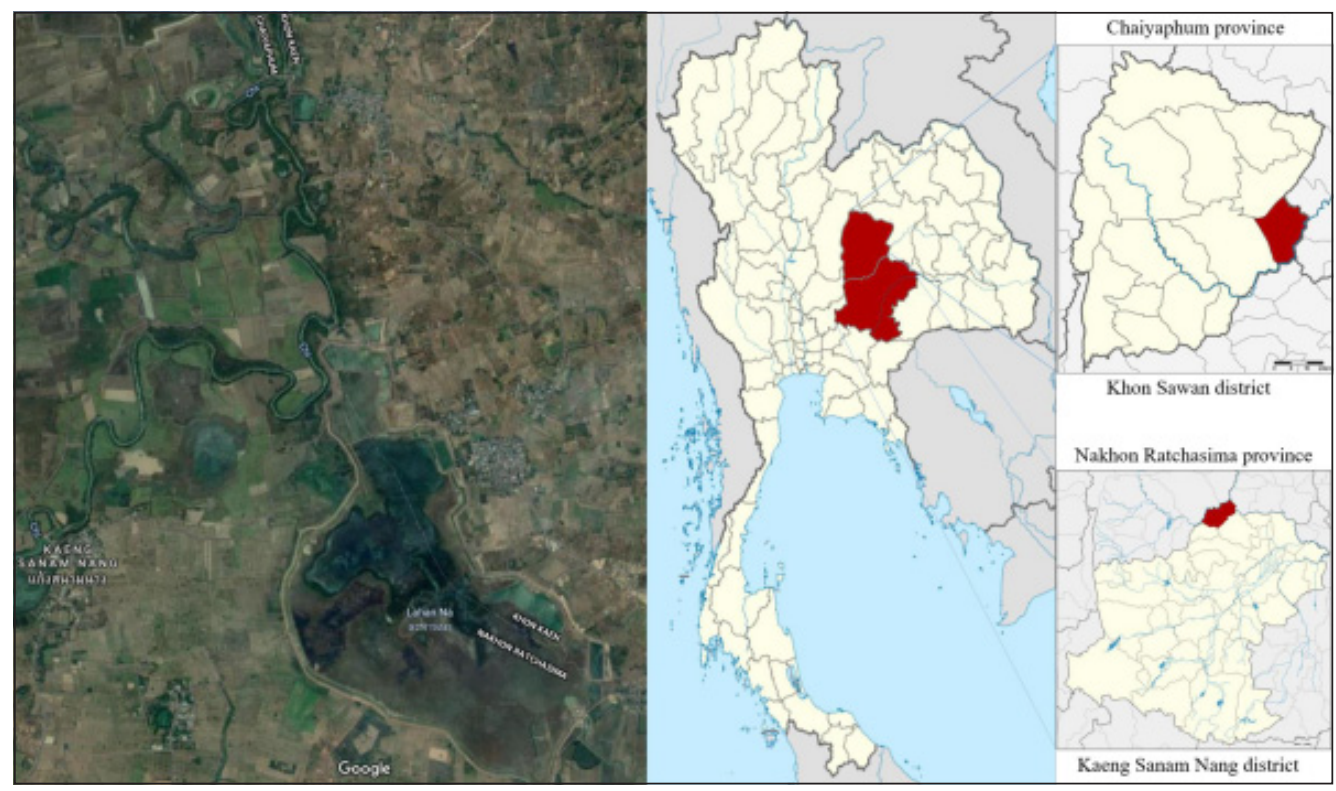

Figure 1. Map of Thailand showing the study area in Chaiyaphum and Nakhon Ratchasima provinces, Thailand.

laboratory at the Parasitic Disease Research Center (PDRC), Institute of Medicine, Suranaree University of Technology. Each specimen was prepared and examined for the presence of intestinal helminth organisms with solvent-free faecal parasite concentrator (Mini Parasep® SF) (Kaewpitoon et al., 2016; Kaewpitoon et al., 2018). Each specimen was examined under a microscope and initially screened with a $10 \times$ objective; the magnification of the low, medium, and high power objectives was $4 \times, 10 \times$, and $40 \times$, respectively. Suspected intestinal helminth objects were subsequently examined under a high-power objective. All samples were examined by two laboratory technologists from the PDRC. Patients who were infected with helminths and other known parasites were treated with anti-intestinal helminthic drugs and asked to attend health education sessions.

\section{Statistical analysis}

Statistical analyses were performed using the computer program STATA for Windows, version 13 (StataCorp LLC, Lakeway Drive, College Station, Texas, USA). The sociodemographic characteristics of the participants are presented as frequencies and percentages for categorical variables. The number of eggs per gram of faeces (epg) was calculated as follows: (number of eggs/ drop $\times$ total number of drops of faecal solution)/(gram of faeces). The intensity of infection was expressed as epg of faeces for each participant. According to the WHO guidelines, the intensity of infection was classified as "light", "moderate" or "heavy" on the basis of the faecal egg count (Elkins et al., 1991; Montresor et al., 1998). The differences in infection between the categorical variables were assessed using the Chi square test. Multivariable logistic regression analysis was performed to estimate the odds ratios (OR) and 95\% confidence intervals $(95 \% \mathrm{CI})$ to assess the associations between potential risk factors and the prevalence of HIs. A P-value of $<0.05$ was considered statistically significant.

\section{RESULTS}

Of the 691 faecal specimens examined, 14 were positive for at least one intestinal helminth, resulting in an overall prevalence of $2.03 \%$. The overall prevalence rate was $2.76 \%(11 / 398)$ in females and $1.02 \%(3 / 293)$ in males. Participants aged 41-50 years had a higher prevalence rate, $3.53 \%$ (7/198), than 
participants in the other age groups. Participants who had attended secondary school had a higher prevalence rate, $2.52 \%$ $(6 / 238)$, than participants in the other education groups. A high prevalence of helminths was found in participants who are housewives $(5.55 \%, 1 / 18)$. When the participants were classified by occupation, HIs were most frequent among those with income levels of $\leq 5,000 \mathrm{Baht} / \mathrm{month}$, at $3.70 \%$ (9/216). By location, participants from the Kok Mang Ngoy subdistricts had a higher prevalence rate, $2.81 \%$ (6/213), than participants in the Bueng Phalai 2.27\% (4/176), Bueng Samrong 2.17\% (2/92) and Yang Wai $0.95 \%(2 / 210)$ subdistricts.
However, there was no significant difference between the prevalence of infection for each district. The socio-demographic characteristics of the participants and HIs were analysed for each variable using the Chi-square test; there were no significant differences between the prevalence of helminths for each characteristic. The influence of sociodemographic characteristics on the prevalence of helminths is shown in Table 1. Six species of helminths were identified; 3 species were identified as FBHs, and 3 species were the other STHs (Figure 2). FBHs were among the most common helminths, including $O$. viverrini, at $1.30 \%$ (9/689); minute intestinal fluke, at

Table 1. Positive rate of intestinal helminthic eggs categorized by general characteristics $(\mathrm{n}=691)$

\begin{tabular}{|c|c|c|c|c|c|}
\hline Variables & $\begin{array}{c}\text { No. Samples } \\
\text { n (\%) }\end{array}$ & $\begin{array}{c}\text { No. positive } \\
\text { n (\%) }\end{array}$ & $\begin{array}{l}\text { Infection } \\
\text { rate }(\%)\end{array}$ & $\begin{array}{c}\text { Chi-square } \\
\text { test }\end{array}$ & P-value \\
\hline \multicolumn{6}{|l|}{ Gender } \\
\hline Male & $293(42.40)$ & $3(1.02)$ & 0.43 & 0.110 & 2.555 \\
\hline Female & $398(57.59)$ & $11(2.76)$ & 1.59 & & \\
\hline \multicolumn{6}{|l|}{ Age (yr) } \\
\hline$\leq 20$ & $4(0.58)$ & 0 & & 0.787 & 3.934 \\
\hline$\overline{2} 1-30$ & $13(1.88)$ & 0 & & & \\
\hline $31-40$ & $60(8.68)$ & $1(1.66)$ & 0.14 & & \\
\hline $41-50$ & $198(28.65)$ & $7(3.53)$ & 1.01 & & \\
\hline $51-60$ & $249(36.03)$ & $3(1.20)$ & 0.43 & & \\
\hline$>60$ & $167(24.17)$ & $3(1.79)$ & 0.43 & & \\
\hline \multicolumn{6}{|l|}{ Education } \\
\hline Illiterate & $8(1.16)$ & 0 & 0 & 0.907 & 1.018 \\
\hline Primary & $417(60.34)$ & $8(1.92)$ & 1.16 & & \\
\hline Secondary & $238(34.44)$ & $6(2.52)$ & 0.87 & & \\
\hline Diploma & $8(1.16)$ & 0 & 0 & & \\
\hline Academic & $20(2.89)$ & 0 & 0 & & \\
\hline \multicolumn{6}{|l|}{ Job Status } \\
\hline Famer & $562(81.33)$ & $11(1.96)$ & 1.59 & 0.803 & 2.319 \\
\hline Employed & $68(9.84)$ & $2(2.94)$ & 0.29 & & \\
\hline Trade & $17(2.46)$ & 0 & 0 & & \\
\hline Housewife & $18(2.60)$ & $1(5.55)$ & 0.14 & & \\
\hline Government officer & $16(2.31)$ & 0 & 0 & & \\
\hline Other & $10(1.44)$ & 0 & 0 & & \\
\hline \multicolumn{6}{|l|}{$\begin{array}{l}\text { Family Income } \\
(\$, \text { per month })\end{array}$} \\
\hline$\leq 5,000$ & $216(31.25)$ & $9(3.70)$ & 0.14 & 0.998 & 20.331 \\
\hline$\overline{5}, 001-10,000$ & $83(12.01)$ & $3(3.61)$ & 0.43 & & \\
\hline $10,001-15,000$ & $13(1.88)$ & 0 & 0 & & \\
\hline $15,001-20,000$ & $14(2.02)$ & $1(7.14)$ & & & \\
\hline$>20,000$ & $16(2.31)$ & 0 & & & \\
\hline Unknown & $349(50.50)$ & $1(0.29)$ & & & \\
\hline \multicolumn{6}{|l|}{ Location (sub district) } \\
\hline Yang Wai & $210(30.39)$ & $2(0.95)$ & & 0.582 & 1.955 \\
\hline Kok Mang Ngoy & $213(30.82)$ & $6(2.81)$ & & & \\
\hline Bueng Phalai & $176(25.47)$ & $4(2.27)$ & & & \\
\hline Bueng Samrong & $92(13.31)$ & $2(2.17)$ & & & \\
\hline
\end{tabular}

Data are presented as frequencies (\%). *Chi-square. 


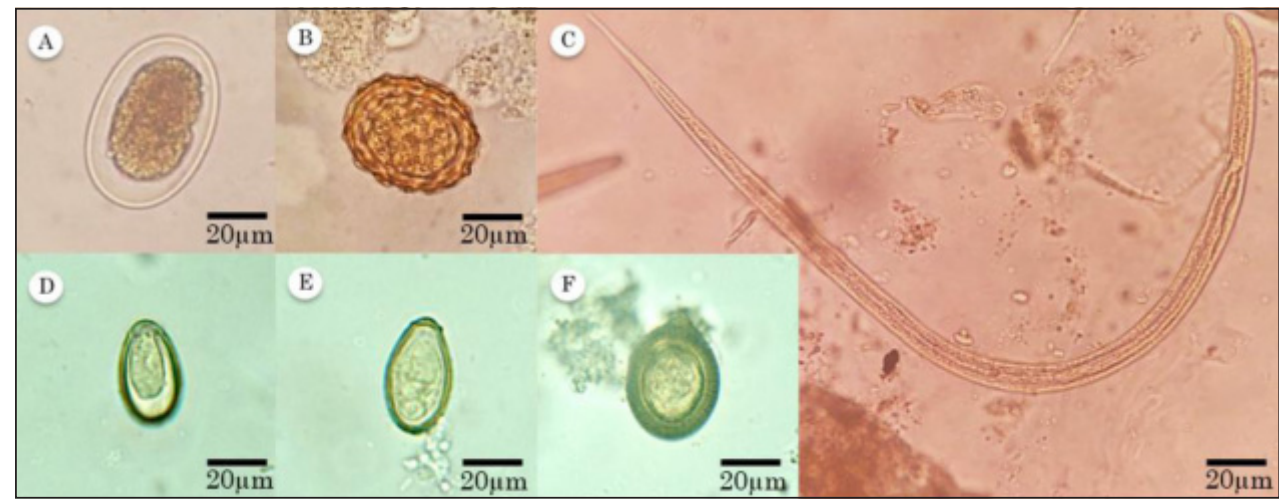

Figure 2. Morphology of intestinal helminth eggs and larvae identified by light microscopy in faecal samples.

(A) Hookworm egg $(\times 400)$. (B) Ascaris lumbricoides egg $(\times 400)$. (C) Strongyloides stercoralis larvae $(\times 100)$. (D) Minute intestinal fluke egg $(\times 400)$. (E) Opisthorchis viverrini egg $(\times 400)$. $(\mathrm{F})$ Taenia spp. egg $(\times 400)$.

Table 2. Intestinal helminth infection among 691 rural villagers in Chaiyaphum and Nakhon Ratchasima provinces, northeastern Thailand

\begin{tabular}{lcc}
\hline Type of Intestinal Helminth & No. positive & Prevalence (\%) \\
\hline Opisthorchis viverrini & 9 & 1.31 \\
Strongyloides stercoralis & 3 & 0.44 \\
Ascaris lumbricoides & 2 & 0.29 \\
Hookworm & 1 & 0.15 \\
Teania spp. & 1 & 0.15 \\
Minute intestinal fluke & 1 & 0.15 \\
\hline Total & $\mathbf{1 7}$ & $\mathbf{2 . 4 6}$ \\
\hline
\end{tabular}

*Co-infection 3 cases.

Table 3. Egg counts (eggs per gram of faeces) used to describe the intensity of infection $(\mathrm{n}=691)$

\begin{tabular}{lcc}
\hline Type of Intestinal Helminth & $\begin{array}{c}\text { Intensity of infection } \\
\text { (egg count per gram) }\end{array}$ & Level of intensity \\
\hline Strongyloides stercoralis & 460.33 & light \\
Hookworm & 381.75 & light \\
Opisthorchis viverrini & 100.50 & light \\
Teania spp. & 28.00 & light \\
Minute intestinal fluke & 25.00 & light \\
Ascaris lumbricoides & 24.00 & light \\
\hline
\end{tabular}

$0.15 \%$ (1/689); and Taenia spp. at $0.15 \%$ (1/689). STHs were identified as $S$. stercoralis, at $0.44 \%$ (3/689); A. lumbricoides, at $0.29 \%$ (2/689); and hookworm, at $0.15 \%$ (1/689). Three cases were found to have coinfections, including 2 cases of $S$. stercoralis and hookworm and 1 case of $O$. viverrini and $S$. stercoralis infection. The types of HIs are shown in Table 2. Of the 14 infected participants, all had light infection with $S$. stercoralis, O. viverrini, hookworm, minute intestinal fluke, Taenia spp. and A. lumbricoides. The summary of HI intensity in Table 3 shows that there were no heavy or moderate infections. Sociodemographic characteristics associated with HIs were analysed using multivariable logistic regression analysis, as shown in Table 4. 


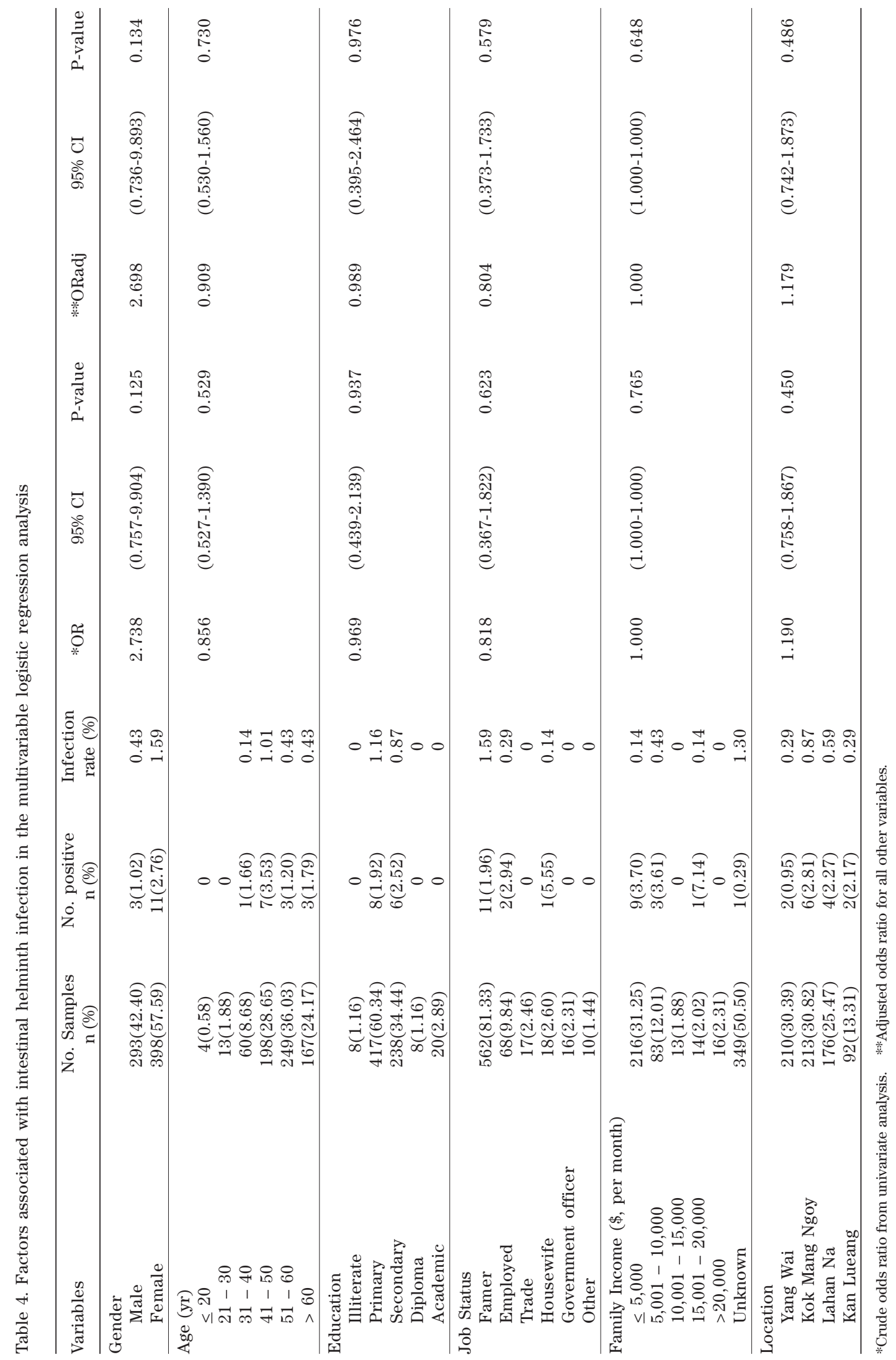


No significant association was found between HIs and the participants' general characteristics $(\mathrm{P}>0.05)$.

\section{DISCUSSION}

HIs are an important public health problem in many countries, including Thailand. People with infections of heavier intensity can exhibit a range of symptoms, including intestinal manifestations, abdominal pain and diarrhoea, general malaise and weakness, malnutrition, and impaired growth and physical development. Infections of very high intensity can cause intestinal obstruction that should be treated surgically. Patients with a light infection intensity usually do not suffer from the infection (World Health Organization, 2018). Therefore, active screening is required for rural communities where there remains a lack of hygiene and an inadequate supply of sanitary water (Boonjaraspinyo et al., 2013) and to ensure that mass drug administration is provided to populations at risk for HIs. Studies conducted with participants living throughout Thailand during a national survey of HIs have reported that the overall prevalence of HIs was 18.1\% (Wongsaroj et al., 2014). Here, the overall prevalence of HIs among the entire tested participant group living in rural communities in the Khon Sawan district, Chaiyaphum province and Kaeng Sanam Nang district, Nakhon Ratchasima province, was 2.03\%. This result was slightly lower or comparable to the findings of a current national survey of HIs in Thailand. These results were compared to those of other studies, and the recent infection rates reported in these studies were lower than those previously reported among gardeners who were studied in Nakhon Ratchasima (Kaewpitoon et al., 2015; Kaewpitoon et al., 2016), Khon Kaen (Kaewpitoon et al., 2015; Kaewpitoon et al., 2019), and Chachoengsao provinces (Suntaravitun and Dokmaikaw, 2018). Prevention and control campaigns by health personnel, health volunteers, community leaders, and local university staff for HIs, especially $O$. viverrini, in these areas were launched five years ago. The infection rate of HIs has decreased, which might be due to the continuous campaign that possibly affected the population. Our study demonstrated that FBHs and STHs were found frequently in both sexes and were not significantly associated with the prevalence of helminths. The infection rate was slightly higher in females than in males. A high prevalence of intestinal helminths was found in participants that are housewives. This result was similar to previous findings (Graczyk and Fried, 1998). Although the patterns of other food-borne trematodiases have changed in Asia following changes in habits, cultural practices, health education, industrialization, and environmental alteration, human echinostomiasis remains a health problem. The disease is most prevalent in remote rural places among lowwage earners and in women of childbearing age. In a recent study, the sex difference may be due to female-specific cultural roles and tasks, such as taking risks with their work on the farm, catching shrimp, fish, and snails and gathering water and fresh vegetables along the river or water reservoir, or eating raw meat during cooking. Rural female cultural roles include collecting food materials in the areas around their villages and cooking for their family. In our study, the prevalence of HIs in older people was higher than that in young people (age $<40$ years). This result is similar to that of previous studies showing that older people need to be screened for HIs. Kaewpitoon et al. (2019) reported that the prevalence of HIs in older people was higher than that in young people (age $<51$ years). In addition, Suntaravitun and Dokmaikaw (2018) and Boonjaraspinyo et al. (2013) reported that the prevalence of HIs was higher in male participants $>40$ years of age than in young people. Moreover, Rangsin et al. (2009) reported that the prevalence of $O$. viverrini infection was correlated with an age of $>60$ years. This correlation may arise because older people have poorer education, live in conditions of poor sanitation, and partake in the culturally embedded habit of eating uncooked food (Songserm et al., 2012). Health education programmes should target this group and teach individuals about the benefits of 
wearing shoes and discontinuing risky eating habits. In the stratification by educational level, the highest prevalence rate was found for those who attended secondary school, followed by those who attended primary school. There was no significant difference among all education categories. However, health literacy is a concern in the secondary school group. Padchasuwan et al. (2018) indicated that health literacy can be used as a desirable strategy among secondary school students in Northeastern Thailand for informing those with a lower practice level of liver fluke prevention and control. The behavioural intervention is focused on cognitive skills, communication skills, and media literacy skills for this group. Ross $e t$ $a l$. (2012) reported that low socioeconomic status, poor sanitation, and proximity to water sources were all reliable indicators of infection status in Northern Samar, Philippines. In addition, Muslim et al. (2019) reported that low socioeconomic status was highly associated with STH infections in some parts of Malaysia, while socioeconomic development has shown a significant reduction in intestinal parasitism in the general population. Our study is similar to those studies in which HIs were most frequent among individuals with incomes of $\leq 5,000$ Baht/month. This result will aid in the targeting of limited income groups for treatment and health education efforts. Our data indicated that HIs were found in all subdistricts located around the Chi River and Lahanna fresh water reservoir. There was no significant difference between the prevalence of infection for each district. A previous study reported that $\mathrm{HI}$ infection was associated with the lower land near the Lahanna fresh water reservoir, Waeng Noi district, Khon Kaen province, Northeastern Thailand. This study indicated that lower elevation was associated with a higher infection rate than higher elevations. Loam and clay loam soils are associated with lower odds of A. lumbricoides infection, while sandy loam soils are associated with increased odds of Necator americanus infection (Wardell et al., 2017). The porosity of sand provides a favourable environment for hookworm survival, offering drainage during wet conditions to prevent hookworm larvae from being waterlogged while also enabling hookworm larvae to migrate downward to prevent desiccation during hot and dry conditions (Wardell et al., 2017; Brooker and Michael, 2000). Ribas et al. (2017) reported intestinal parasitic infections and environmental water contamination in a rural village of northern Lao's PDR. The level of microbial pathogen contamination was associated with human activity, with greater levels of contamination found at the downstream site than at the village and upstream sites, and the microbial population included several pathogenic microbes that were detected in the local river, a natural water source for consumption in the village. Basically, adequate warmth and moisture are key features for each of the STHs and FBHs. Wetter areas area associated with increased transmission, and in some endemic areas, both STH infections exhibit marked seasonality (Brooker and Michael 2000). However, a recent study showed that location was not significantly associated with the prevalence of intestinal helminths. However, there were infections with STHs and FBHs in all districts. Therefore, more efforts from local administrations, particularly health education campaigns for villagers, are required for prevention strategies to minimize HIs and improve sanitation conditions and, consequently, the general health of the villagers.

Six species of intestinal helminths were identified from the faecal specimens of this study; 3 species were identified as FBHs, and 3 species were STHs. FBHs were among the most common intestinal helminths, including O. viverrini, at $1.30 \%$, which was the highest prevalence in this study, but the prevalence of this was lower than that reported in a previous study. The national prevalence rate of $O$. viverrini was reported at $5.1 \%$ among 15,555 Thais, which was the highest prevalence in certain areas of the country (Wongsaroj et al., 2014). Kaewpitoon et al. (2018) reported that the prevalence of $O$. viverrini infection among a rural Thai population of 560 individuals from Nakhon Ratchasima, Khonkaen, and Chaiyaphum provinces was 2.86\%. In addition, Kaewpitoon 
et al. (2016) reported the prevalence of $O$. viverrini infection among 978 villagers in the border areas of three provinces in northeastern Thailand. O. viverrini infection was found in $1.74 \%$ of those tested, and the majority of positive cases were found in participants who lived in the Khon Sawan district (8.43\%), Chaiyaphum province and Kaeng Sanam Nang district (1.84\%), or Nakhon Ratchasima province. These results indicate that $O$. viverrini still exists in rural parts of Thailand, which raises concerns regarding public health. Other FBHs included minute intestinal fluke (0.15\%) and Taenia spp. (0.15\%), which showed the lowest prevalence in this study. Wongsaroj et al. (2014) reported that the national prevalence rate of minute intestinal fluke was $1.6 \%$. $O$. viverrini infection was the most prevalent infection in certain areas of the country. A previous study reported the pattern of trematode infection with $O$. viverrini and other minute intestinal flukes that coexist in endemic areas. Sato et al. (2015) analysed the patterns of infections of $O$. viverrini and $H$. taichui, a minute intestinal fluke, in Lahanam and Thakhamlien villages (Savannakhet province, Lao PDR) in two cross-sectional investigations. Out of a total of 207 human participants, post-anthelmintic treatment positivity rates for expelled worms were 170 (82.1\%) for H. taichui and 65 (31.4\%) for O. viverrini. Both of these species coexist in the study villages. In addition, minute intestinal fluke infection, especially haplorchiasis (74\%), is more common in northern Thailand. The high prevalence of haplorchiasis in Nan and Lampang provinces, Thailand, was proven by adult worm recovery from suspected opisthorchiasis cases. It was found that 39 of 50 cases (78.0\%) from Nan Province had $H$. taichui, with intensities ranging from 5 to 1,250 with an average of 62 worms/case (Wijit et al., 2013). Moreover, Wongsawad et al. (2012) demonstrated the mixed infection of $O$. viverrini and $H$. taichui and confirmed the extended distribution of $O$. viverrini and minute intestinal fluke in Northern Thailand. However, the eggs of Opisthorchis and minute intestinal infections are easily confused under a microscope unless specific techniques are used (Kaewkes et al., 1991; Tesana et al., 1991; Sukontason et al., 1999; Wijit et al., 3013). Therefore, worm recovery after anthelminthic treatment or molecular techniques should be used for confirmation in endemic areas. Taenia spp. infection had the lowest prevalence in this study. The prevalence of this was similar to that reported in a previous study. Wongsaroj et al. (2014) reported the national prevalence rate of Taenia spp. was $0.7 \%$. The prevalence of Taenia spp. infection was 0.5\% among 199 faecal samples submitted for routine examination in the clinical pathology laboratory of Suranaree University of Technology Hospital, Nakhon Ratchasima province, Thailand (Kaewpitoon et al., 2016). In addition, in 209 faecal samples were analysed in rural areas of Nakhon Ratchasima province, Thailand, and the prevalence of Taenia spp. infection was 0.48\% (Kaewpitoon et al., 2015). However, Kaewpitoon et al. (2018) reported the prevalence rate of Taenia spp. was 2.5\% among 400 rural areas in Khon Kaen province, northeastern Thailand. These results indicate that people still have the culturally embedded habit of eating uncooked meat and have poor education. Health education programmes should target this group and teach individuals about risky eating habits. The findings from our study showed that STHs were identified as $S$. stercoralis (0.44\%), A. lumbricoides (0.29\%) and hookworm (0.15\%). The prevalence of $S$. stercoralis infections has been surveyed in rural communities in Thailand. Laoraksawong et al. (2019) reported that the prevalence rate of $S$. stercoralis was $23.0 \%$ among 526 rural villagers. Suntaravitun and Dokmaikaw (2018) reported that the prevalence rate of $S$. stercoralis was $5.0 \%$ among 224 inhabitants from rural communities. The national prevalence of S. stercoralis was $1.7 \%$, and a national crosssectional survey was conducted in 75 provinces (Wongsaroj et al., 2014). Although the prevalence rate of $S$. stercoralis was low in this study, strongyloidiasis can lead to gastrointestinal symptoms, dermatological 
symptoms, hyperinfection, or fatal outcomes (Grove, 1996; Forrer et al., 2017). Additionally, chronic strongyloidiasis can lead to malnutrition in children and adolescents, causing growth retardation (Forrer et al., 2017). Therefore, awareness campaigns and appropriate control programmes should be developed to reduce strongyloidiasis, especially in farmers and housewives in rural communities. Other STHs, including A. lumbricoides (0.29\%) and hookworm $(0.15 \%)$, had a slight prevalence in this study. The prevalence of infection with these prevalent STHs was lower than that reported in other studies in Thailand, mainly that of Suntaravitun and Dokmaikaw (2018), who reported that the prevalence of $A$. lumbricoides was $1.3 \%$. Kaewpitoon et al. (2018) showed that A. lumbricoides prevalence was $0.75 \%$ among villagers living in rural areas. Comparison of our current data and the national survey of Thailand data from 2014 (Wongsaroj et al., 2014) showed that our study found a slightly lower prevalence of $A$. lumbricoides (0.5\%) than the national survey. Previous studies reported a high prevalence of hookworms by specialists. In addition, hookworm infection was lower in our study than in other studies. Kaewpitoon et al. (2019) indicated that hookworm infection was commonly found among villagers from Khon Kean province, Thailand. Punsawad et al. (2017) reported the high prevalence of intestinal parasitic infection and associated risk factors among village health volunteers in rural communities of southern Thailand. These studies showed that hookworm infection is more prevalent than other types of STH infection. Hookworms are an STH with a direct life cycle, and the main route of exposure is contact with larvae-contaminated soil due to a lack of footwear (Ribas $e t$ al., 2017). Therefore, preventive measures should be taken to improve the health of the people against such helminths. Our study found that three cases were coinfections for $S$. stercoralis and hookworm. The two parasites have the same infection route, i.e., skin penetration. Both parasites are mostly prevalent in rural areas with poor sanitation conditions and a warm and humid climate that favours larvae survival in the environment (Brooker et al., 2004; Hotez et al., 2008; Schär et al., 2013). Forrer et al. (2018) reported that $43.8 \%$ of the cases were coinfections between $S$. stercoralis and hookworm among 2,576 participants in 60 villages of Preah Vihear Province, Cambodia. Both parasites were ubiquitous in the province, with coinfections accounting for almost half of all cases. Coinfection risk was positively associated with longer walking distances to a health centre and exhibited a small clustering tendency. S. stercoralis and hookworm infections are important health problems and are major contributors to morbidity and mortality in the developing world (Becker et al., 2011). Wesolowska et $a l$. (2018) presented unusual dual $S$. stercoralis and hookworm infections in a traveller from Poland - a low-prevalence country - during low-budget travel in Southeast Asia. Strongyloides and hookworm infestations are rare in moderate climate zones and primarily occur in tropical and subtropical areas. Therefore, current information underscores that $S$. stercoralis and hookworm must not be neglected. Our study showed that 1 case presented coinfection with $O$. viverrini and $S$. stercoralis. This is found frequently in rural areas of Thailand. Laoraksawong $e t$ $a l$. (2019) evaluated the prevalence of $S$. stercoralis and $O$. viverrini infections in rural communities in northeast Thailand. The overall prevalence of $S$. stercoralis infection was $23.0 \%$. The prevalence of $O$. viverrini infection was $19.4 \%$. This study demonstrated that the updated prevalence of intestinal parasite infections is still high in rural communities in northeast Thailand, especially strongyloidiasis and opisthorchiasis. Moreover, Boonjaraspinyo et al. (2013) demonstrated coinfection of S. stercoralis and O. viverrini among rural communities in northeastern Thailand at $3.3 \%(8 / 253)$. The study demonstrated that the prevalence of $S$. stercoralis and $O$. viverrini has not declined. These results indicated that the majority of the participants had a light infection of STHs and FBHs. None of the participants had a heavy HI intensity. The 
light intensity of HIs in the present study may be due to differences in the study population, general living conditions, and the accessibility of health services. In general, the majority of people infected with HIs have a light infection intensity and no symptoms. The participants who were infected with these HIs were informed and treated following the Centers for Disease Control and Prevention, Ministry of Public Health recommendations regarding the type of $\mathrm{HI}$. In Thailand, the cost of anti-parasitic drugs is generally low (Suntaravitun and Dokmaikaw et al., 2018; Boonjaraspinyo et al., 2013; Punsawad et al., 2017).

\section{CONCLUSIONS}

In conclusion, our results show a prevalence rate of HIs among inhabitants living around the Chi River and Lahanna fresh water reservoir. These infections result mainly from foodborne helminths and skin-penetrating nematodes. Therefore, interventions should concentrate on the personal hygiene of the population and improving sanitation to reduce HIs in this area.

Acknowledgements. We are grateful to all participants, heads of villages, and local health officers in the Khon Sawan district, Chaiyaphum province, and in the Kaeng Sanam Nang district, Nakhon Ratchasima province, northeastern Thailand, for participating and assisting in this study.

\section{FINANCIAL SUPPORT}

The present study was supported by the National Research Council of Thailand (NRCT) for fiscal year 2018 and by the SUT research and development fund of the Suranaree University of Technology (SUT), Thailand.

\section{CONFLICT OF INTERESTS}

The authors declare that there are no conflicts of interest.

\section{REFERENCES}

Becker, S.L., Sieto, B., Silué, K.D., Adjossan, L., Koné, S., Hatz, C., Kern, W.V., N'Goran, E.K. \& Utzinger, J. (2011). Diagnosis, clinical features, and self-reported morbidity of Strongyloides stercoralis and hookworm infection in a Coendemic setting. PLOS Neglected Tropical Diseases 5: e1292.

Boonjaraspinyo, S., Boonmars, T., Kaewsamut, B., Ekobol, N., Laummaunwai, P., Aukkanimart, R., Wonkchalee, N., Juasook, A. \& Sriraj, P. (2013). A crosssectional study on intestinal parasitic infections in rural communities, northeast Thailand. Korean Journal of Parasitology 51: 727-734.

Brooker, S., Bethony, J. \& Hotez, P.J. (2004). Human hookworm infection in the $21^{\text {st }}$ century. Advances in Parasitology 58:197-288.

Brooker, S. \& Michael, E. (2000). The potential of geographical information systems and remote sensing in the epidemiology and control of human helminth infections. In: Hay, S.I., Rogers, D.J. \& Randolph, S.E. (2000). Remote sensing and geographical information systems in epidemiology. Advances in Parasitology 47: 245-288.

Elkins, D.B., Sithithaworn, P., Haswell-Elkins, M., Kaewkes, S., Awacharagan, P. \& Wongratanacheewin, S. (1991). "Opisthorchis viverrini: relationships between egg counts, worms recovered and antibody levels within an endemic community in northeast Thailand." Parasitol 102: 283-288.

Forrer, A., Khieu, V., Schär, F., Hattendorf, J. Marti, H., Neumayr, A., Char, M.C., Hatz C., Muth, S. \& Odermatt, P. (2017). Strongyloides stercoralis is associated with significant morbidity in rural Cambodia, including stunting in children. PLOS Neglected Tropical Diseases 11: $\mathrm{e} 0005685$. 
Forrer, A., Khieu, V., Schär, F., Vounatsou, P., Chammartin, F., Marti, H., Muth, S. \& Odermatt, P. (2018). Strongyloides stercoralis and hookworm co-infection: spatial distribution and determinants in Preah Vihear province, Cambodia. Parasites \& Vectors 11: 33.

Graczyk, T.K. \& Fried, B. (1998). Echinostomiasis: a common but forgotten food-borne disease. American Journal of Tropical Medicine and Hygiene 58: 501-504.

Grove, D.I. (1996). Human strongyloidiasis. Advances in Parasitology 38: 251-309.

Hotez, P.J., Brindley, P.J., Bethony, J.M., King, C.H., Pearce, E.J. \& Jacobson, J. (2008). Helminth infections: the great neglected tropical diseases. Journal of Clinical Investigation 118: 1311-1321.

Hotez, P.J., Bottazzi, M.E., Strych, U., Chang, L.Y., Lim, Y.A., Goodenow, M.M. \& AbuBakar, S. (2015). Neglected tropical diseases among the association of Southeast Asian Nations (ASEAN): Overview and Update. PLOS Neglected Tropical Diseases 9: e0003575.

International Agency for Research on Cancer (IARC). IARC monographs on the evaluation of carcinogenic risks to humans. Lyon: World Health Organization, International Agency for Research on Cancer, 2011.

Kaewkes, S., Elkins, D., Sithithaworn, P. \& Haswell-Elkins, M.R. (1991). Comparative studies on the morphology of the eggs of Opisthorchis viverrini and lechithodendriid trematodes. Southeast Asian Journal of Tropical Medicine and Public Health 22: 623-630.

Kaewpitoon, N., Kaewpitoon, S., Meererksom, T., Chan-Aran, S., Sangwalee, W., Norkaew, J., Chuatanam, J., Kujapan, J., Padchasuwan, N., Tongtawee, T., Matrakool, L., Loyd, R. \& Wakkhuwatthapong, P. (2018). Detection of Opisthorchis viverrini infection among the ASEAN population in Thailand using a verbal screening test and fecal concentrator kit. Iranian Journal of Parasitology 13: 258266.
Kaewpitoon, N., Kaewpitoon, S., Meererksom, T., Chan-Aran, S., Sangwalee, W., Kujapun, J., Norkaew, J., Chuatanam, J., Ponpimai, S., Pothipim, M., Padchasuwan, N., Tongtawee, T., Matrakool, L., Panpimanmas, S., Loyd, R.A. \& Wakkhuwatthapong, P. (2018). Detection of risk groups for carcinogenic liver fluke infection by verbal screening questionnaire using a mobile application. Asian Pacific Journal of Cancer Prevention 19: 2013-2019.

Kaewpitoon, S.J., Loyd, R.A. \& Kaewpitoon, N. (2015). A cross-sectional survey of intestinal helminthiases in rural communities of Nakhon Ratchasima province, Thailand. Journal of Medical Association of Thailand 98: S27-32.

Kaewpitoon, S.J., Rujirakul, R., Tongtawee, T., Matrakul, L., Panpimanmas, S., Wakkuwattapong, P., Loyd, R.A. \& Kaewpitoon, N. (2016). Detection of the carcinogenic liver fluke Opisthorchis viverrini using a mini parasep sf faecal parasite concentrator. Asian Pacific Journal of Cancer Prevention 17: 373376.

Kaewpitoon, S.J., Rujirakul, R., Wakkuwattapong, R., Matrakool, L., Tongtawee, T., Panpimanmas, S., Pengsaa, P., Jomkoa, D., Joosiri, A. \& Kaewpitoon, N. (2016). Opisthorchis viverrini infection among people in the border areas of three provinces, northeast of Thailand. Asian Pacific Journal of Cancer Prevention 17: 2973-2977.

Kaewpitoon, S.J., Ponphimai, S., Petdee, P., Thueng-in, K., Khiaowichit, J., Meererksom, T., Wakkhuwatapong, P., Bukkhunthod, P., Leng, M., Namhong, T., Taweepakdeechot, A., Yardcharoen, N., Panithanang, B., Srithongklang, W., Panpimanmas, S. \& Kaewpitoon, N. (2019). The prevalence of intestinal helminthic infection in rural villagers, Northeastern Thailand. Tropical Biomedicine 36: 152-164. 
Laoraksawong, P., Sanpool, O., Rodpai, R., Thanchomnang, T., Kanarkard, W., Maleewong, W., Kraiklang, R. \& Intapan, P.M. (2018). Current high prevalences of Strongyloides stercoralis and Opisthorchis viverrini infections in rural communities in northeast Thailand and associated risk factors. BMC Public Health 18: 940.

Montresor, A., Crompton, D.W.T., Hall, A., Gyorkos, T.W. \& Lorenzo, S. 1998. Guidelines for The evaluation of soiltransmitted helminthiasis and schistosomiasis at community level. Geneva: World Health Organization; 1998. WHO document WHO/CDS/SIP/98. 1 (available from the program parasitic diseases and vector control, World Health Organization, CH1211Geneva 27, Switzerland).

Muslim, A., Sofian ,M.S., Shaari, S.A., Hoh, B.P. \& Lim, Y.A.L. (2019). Prevalence, intensity and associated risk factors of soil transmitted helminth infections: A comparison between Negritos (indigenous) in inland jungle and those in resettlement at town peripheries. PLOS Neglected Tropical Diseases 13: e0007331.

Padchasuwan, N., Banchonhattakit, P. \& Kaewpitoon, N. (2018). Health literacy associated with liver fluke prevention and control among secondary school students in northeast Thailand. Suranaree Journal of Science and Technology 25: 307-318.

Punsawad, C., Phasuk, N., Bunratsami, S., Thongtup, K., Siripakonuaong, N. \& Nongnaul, S. (2017). Prevalence of intestinal parasitic infection and associated risk factors among village health volunteers in rural communities of southern Thailand. BMC Public Health 17: 564 .

Rangsin, R., Mungthin, M., Taamasri, P., Mongklon, S., Aimpun, P., Naaglor, T. \& Leelayoova, S. (2009). Incidence and risk factors of Opisthorchis viverrini infections in a rural community in Thailand. American Journal of Tropical Medicine and Hygiene 81: 152-155.
Ribas, A., Jollivet, C., Morand, S., Morand, S. Thongmalayvong, B., Somphavong, S., Siew, C.C., Ting, P.J., Suputtamongkol, S., Saensombath, V., Sanguankiat, S., Tan, B.H., Paboriboune, P., Akkhavong, K. \& Chaisiri, K. (2017). Intestinal parasitic infections and environmental water contamination in a rural village of northern Lao PDR. Korean Journal of Parasitology 55: 523-532.

Ross, A.G.P., Olveda, R.M., McManus, D.P., Harn, D.A., Chy, D., Li, Y., Tallo, V. \& Ng, S.K. (2012). Risk factors for human helminthiases in rural Philippines. International Journal of Infectious Diseases 54: 150-155.

Sato, M., Pongvongsa, T., Sanguankiat, S., Yoonuan, T., Kobayashi, J., Boupha, B., Nishimoto, F., Moji, K., Sato, M.O. \& Waikagul, J. (2015). Patterns of trematode infections of Opisthorchis viverrini (Opisthorchiidae) and Haplorchis taichui (Heterophyidae) in human populations from two villages in Savannakhet Province, Lao PDR. Journal of Helminthology 89: 439-445.

Schär, F., Trostdorf, U., Giardina, F., Khieu, V., Muth, S., Marti, H., Vounatsou, P. \& Odermatt, P. (2013). Strongyloides stercoralis: Global distribution and risk factors. PLOS Neglected Tropical Diseases 7: e2288.

Songserm, N., Promthet, S., Wiangnon, S. \& Sithithaworn, P. (2012). Prevalence and co-infection of intestinal parasites among Thai rural residents at high-risk of developing cholangiocarcinoma: a cross-sectional study in a prospective Cohort study. Asian Pacific Journal of Cancer Prevention 13: 6175-6179.

Sukontason, K., Piangjai, S., Sukontasun, K. \& Chaithong, U. (1999). Potassium permanganate staining for differentiation of the surface morphology of Opisthorchis viverrini, Haplorchis taichui and Phaneropsolus bonnei eggs. Southeast Asian Journal of Tropical Medicine and Public Health 30: 371-374. 
Suntaravitun, P. \& Dokmaikaw, A. (2018). Prevalence of intestinal parasites and associated risk factors for infection among rural communities of Chachoengsao province, Thailand. Korean Journal of Parasitology 56: 3339.

Tesana, S., Srisawangwonk, T., Kaewkes, S., Sithithaworn, P., Kanla, P. \& Arunyanart, C. (1991). Eggshell morphology of the small eggs of human trematodes in Thailand. Southeast Asian Journal of Tropical Medicine and Public Health 22: 631-636.

Wardell, R., Clements, A.C.A., Lal, A., Summers, D., Llewellyn, S., Campbell, S.J., McCarthy, J., Gray, D.J. \& V Nery, S. (2017). An environmental assessment and risk map of Ascaris lumbricoides and Necator americanus distributions in Manufahi District, Timor-Leste. PLOS Neglected Tropical Diseases 11: e0005565.
Wijit, A., Morakote, N. \& Klinchid, J. (2013). High prevalence of haplorchiasis in Nan and Lampang provinces, Thailand, proven by adult worm recovery from suspected opisthorchiasis cases. Korean Journal of Parasitology 51: 767-9.

Wongsaroj, T., Nithikathkul, C., Rojkitikul, W., Nakai, W., Royal, L. \& Rammasut, P. (2014). National survey of helminthiasis in Thailand. Asian Biomedicine 8: 779783.

Wongsawad, C., Phalee, A., Noikong, W., Chuboon, S. \& Nithikathkul, C. (2012). Co-infection with Opisthorchis viverrini and Haplorchis taichui detected by human fecal examination in Chomtong district, Chiang Mai Province, Thailand. Parasitology Intermational 61: 56-59.

World Health Organization. (2018). Soiltransmitted helminthic infections. Retrieved May 10, 2018, from http://www. who.int/news-room/fact-sheets/detail/ soil-transmitted-helminth-infections, 2018. 